NBER WORKING PAPER SERIES

\title{
HOW THE INTERNET LOWERS PRICES: EVIDENCE FROM MATCHED SURVEY AND AUTO TRANSACTION DATA
}

\author{
Florian Zettelmeyer \\ Fiona Scott Morton \\ Jorge Silva-Risso \\ Working Paper 11515 \\ http://www.nber.org/papers/w11515

\section{NATIONAL BUREAU OF ECONOMIC RESEARCH 1050 Massachusetts Avenue Cambridge, MA 02138} \\ June 2005
}

We thank Eric Anderson, Severin Borenstein, Hai Che, Priya Raghubir, Jose Silva, K. Sudhir, and seminar participants at the University of British Columbia, New York University, University of California at Berkeley, the University of Southern California, and Stanford University for helpful comments. We are particularly indebted to Meghan Busse for extensive comments and suggestions. The views expressed herein are those of the author(s) and do not necessarily reflect the views of the National Bureau of Economic Research.

(C)2005 by Florian Zettelmeyer, Fiona Scott Morton and Jorge Silva-Risso. All rights reserved. Short sections of text, not to exceed two paragraphs, may be quoted without explicit permission provided that full credit, including (C) notice, is given to the source. 
How the Internet Lowers Prices: Evidence from Matched Survey and Auto Transaction Data Florian Zettelmeyer, Fiona Scott Morton and Jorge Silva-Risso

NBER Working Paper No. 11515

July 2005

JEL No. L11, L15, L62, D82, M31

\section{$\underline{\text { ABSTRACT }}$}

There is convincing evidence that the Internet has lowered the prices paid by some consumers in established industries, for example, term life insurance and car retailing. However, current research does not reveal much about how using the Internet lowers prices. This paper answers this question for the auto retailing industry. We use direct measures of search behavior and consumer characteristics to investigate how the Internet affects negotiated prices. We show that the Internet lowers prices for two distinct reasons. First, the Internet helps consumers learn the invoice price of dealers. Second, the referral process of online buying services, a novel institution made possible by the Internet, also helps consumers obtain lower prices. The combined information and referral price effects are $-1.5 \%$, corresponding to $22 \%$ of dealers' average gross profit margin per vehicle. We also find that buyers with a high disutility of bargaining benefit from information on the specific car they eventually purchased while buyers who like the bargaining process do not. The results suggest that the decisions consumers make to use the Internet to gather information and to use the negotiating clout of an online buying service have a real effect on the prices paid by these consumers.

Florian Zettelmeyer Haas School of Business

UC, Berkeley

Berkeley, CA 94720

and NBER

florian@haas.berkeley.edu
Fiona Scott Morton

Yale School of Management

135 Prospect Street

New Haven, CT 06520

and NBER

fiona.scottmorton@yale.edu
Jorge Silva-Risso

Anderson Hall 11

University of California

Riverside, CA 92521

jorge.silva-risso@ucr.edu 


\section{Introduction}

There is convincing evidence that the Internet has lowered the prices paid by some consumers in established industries. In car retailing, for example, Zettelmeyer, Scott Morton, and SilvaRisso (2004) show that new vehicle buyers who use the Internet pay $2.2 \%$ less for their car than those who do not, a savings of $\$ 500$ on the average car. In the insurance industry Brown and Goolsbee (2002) show that the growth of the Internet has reduced the price of term life insurance by $8-15 \%$.

While these results are convincing that using the Internet lowers prices, they do not reveal much about how using the Internet lowers prices. In particular, there are a number of things a buyer can do with the Internet, including researching product characteristics, making price comparisons, communicating with sellers, obtaining recommendations from peers, and so on. Additionally, in some markets, the Internet has made new institutions possible, such as online buying services, that change price negotiations. We would like to better understand what aspects of Internet use matter most for the prices paid by consumers.

We will address this question in the context of price negotiations for new vehicles; we use direct measures of search behavior and consumer characteristics to investigate how the Internet affects negotiated prices in car retailing. We match transaction data on 1,500 car purchases in California with the responses to a survey which asks buyers detailed questions about their Internet usage, their attitudes towards information search and bargaining, and their demographics.

We have two specific goals in this paper. The first goal is to investigate why the Internet lowers the prices paid by consumers who use it. We consider two basic reasons. First, the Internet could be lowering prices by decreasing search cost and thereby making more purchase

relevant information available to consumers who use the Internet. Information can be relevant in various ways. For example, information about invoice prices allow consumers to better estimate 
the dealer's reservation price, an important piece of information in negotiations. Lower search cost may also benefit consumers in their search for low-price dealerships. Because car prices are negotiated and rarely posted, the Internet is unlikely to help consumer find price information from competing dealerships without engaging in direct negotiation. However, the Internet may help consumers find low-price dealerships because it facilitates an information exchange with other consumers about the prices they paid at various dealerships. Also, consumers may make price inferences from dealer websites. To some degree the Internet may be a substitute for visiting multiple dealers.

The second reason we consider is that the Internet could be lowering prices for some consumers by consolidating their buyer power through online buying services; these institutions have become widely accessible as a result of the Internet. There is evidence that groups of buyers should expect to pay lower prices than individual buyers (Snyder 1998). We therefore expect that consumers who use online buying services will pay lower prices.

The second goal of this paper is to determine whether there is an interaction between customer characteristics (such as the disutility of bargaining) and the payoffs from using the Internet. We are interested in this question because there is evidence that consumers who are disadvantaged in the bargaining process are more likely to use the Internet (Zettelmeyer, Scott Morton, and Silva-Risso 2004). The standard economic argument suggests that a consumer's propensity to engage in a given behavior should be positively related to their benefit from doing so. In the present context we therefore expect that consumers with characteristics which disadvantage them in price negotiations will benefit more from using the Internet. For example, consumers who dislike the face-to-face bargaining process might benefit more from getting information from the Internet than consumers who don't mind bargaining.

We show that the Internet lowers prices for two distinct reasons. First, the Internet informs consumers. The information that seems to be most valuable to consumers is the invoice price of the dealer; it enables them to negotiate a low price at a given dealership. Internet information 
seems not to help consumers find low-price dealerships. In particular, the Internet does not substitute for searching at multiple dealers. Second, the referral process of online buying services, a novel institution made possible by the Internet, helps consumers obtain lower prices. We believe that online buying services are effective because, unlike manufacturers, they can exert pressure on dealers by directing incremental business to affiliated dealerships - and away from unaffiliated dealerships.

Our results show combined information and referral price effects of $-1.5 \%$. This corresponds to $22 \%$ of dealers' average gross profit margin per vehicle. We want to highlight two important points concerning these results. First, we account for potential selection effects in search and purchasing behavior by directly controlling for individual buyer characteristics such disutility of bargaining, willingness to search, and car knowledge. While these controls cannot fully rule out selection bias, they increase our confidence that the price effects are not an artifact of differences in unobserved characteristics between people who choose to use the Internet and those who do not. Second, the estimates are close to the estimates of $-2.2 \%$ in Zettelmeyer, Scott Morton, and Silva-Risso (2004), using a different data source, a different estimation method, and a different time period.

We also find that the benefits of gathering information differs by consumer type. While buyers with a high disutility of bargaining pay $1.5 \%$ less when they have collected information on the specific car they eventually purchase than they otherwise would have, buyers who like the bargaining process do not benefit from such information. This stands in contrast to the benefits of requesting a referral from an online buying service, which is equal for the two types of buyers $(-0.7 \%)$. We have argued above that a referral from an online buying service lowers prices at a dealer because of the implicit threat an online buying service can make to redirect customers to the dealer's competitors if the referral service's customers are not offered good prices. Consistent with our findings, if this threat operates, it seems reasonable that it should apply uniformly across consumers. 
Our paper is related to prior work analyzing how consumers search for car information. Ratchford and Srinivasan (1993) use survey data on search and choice behavior from a local automobile market to estimate returns to search time. Moorthy, Ratchford, and Talukdar (1997) present a model of total search effort with an emphasis on how prior brand perception affects the search process. Ratchford, Talukdar, and Lee (2003) analyze how the Internet has changed consumer search behavior for automobiles by comparing data from 1989 and 1999 . Furse, Punj, and Stewart (1984) use a survey to identify clusters of consumers with different search patterns and find that a sizable segment of consumers search very little. Klein and Ford (2001) replicate this approach for a sample of Internet users. These papers have been very useful in informing our survey design. This paper represents a substantial extension of these previous papers on Internet search for automobiles because it combines survey data with detailed transaction data on purchase outcomes.

This paper is also related to Scott Morton, Zettelmeyer, and Silva-Risso (2001) and Zettelmeyer, Scott Morton, and Silva-Risso (2004). These papers are based on a large dataset of transaction prices for new cars which is then combined with information on Internet usage from a large online buying service (Autobytel.com). The first paper provides an overview of Internet car retailing. The second paper controls for selection and shows that using Autobytel.com reduces price by approximately $2.2 \%$. Neither paper addresses the research questions in the present paper. This is because the data used in these papers only contains a single searchor Internet-related explanatory variable, which is whether a consumer used the online buying service Autobytel.com. This service both informs consumers and allows them to submit an online referral. Without other explanatory variables measuring, for example, the extent to which consumers were informed from other sources, these papers cannot determine the effects of different search and purchasing activities. For the same reason these paper cannot disentangle whether consumers save from using the Internet because they become better informed, or because online buying services change the way price negotiations are conducted. 
Scott Morton, Zettelmeyer, and Silva-Risso (2004) use the same dataset here to test predictions from bargaining theory about how private information, patience, and bargaining disutility affect the division of surplus between negotiating parties. That paper has no measures of Internet use and does not consider the role of the Internet for car negotiations.

We proceed as follows. Section 2 describes the survey and transaction data. Section 3 analyzes the different ways in which the Internet lowers prices. Section 4 concludes the paper.

\section{Data}

Our data come from two sources. The first source is a survey instrument which we mailed to 5250 consumers who purchased one of eight popular new car models in California during April and May 2002. We match the individual survey data to transaction data from a data supplier in the automotive industry (henceforth DSA).

\subsection{Survey data}

Survey instrument: The survey asked questions about (1) the number of dealers a buyer visited, (2) the buyer's negotiation strategy, (3) the offline and online sources of information the buyer used, (4) the information the buyer learned at each of these information sources, (5) the referrals the buyer requested, (6) demographics, and (7) personal attitudes towards bargaining and information search. A copy of the survey can be found in the appendix.

Sample: We chose our sample by car type and then mailed the survey to every buyer of the selected car types for whom we had transaction data in April and May 2002. The first objective in selecting car types was to include a variety of car categories (e.g. midsize sedan, luxury sedan, pickup, SUV, etc.). The second objective in selecting car types was to keep the number of different cars small in order to be able to control for car fixed effects without losing too many degrees of freedom. We defined a "car" as the interaction of make, model, body 
type, transmission, displacement, doors, cylinders, and trim level (for example, one "car" is a 2002 Honda Accord sedan with automatic transmission, a 2.2 liter engine, 4 doors, 4 cylinders, and the EX trim). We added the purchases of the most common "cars" for a variety of car categories until we reached our desired sample size. This yielded the most popular variants of Honda Accord, Chrysler PT Cruiser, Nissan Altima, Chevrolet Silverado, Toyota Corolla, Jeep Grand Cherokee, Honda Odyssey, and Chevrolet Tahoe.

Procedure: Each potential respondent received three mailings. The first mailing contained a letter announcing the arrival of the survey, introducing ourselves as the researchers and explaining the purpose of the project. The second mailing was sent out 5 days later and contained a cover letter, the survey, a pre-stamped return envelope, and a $\$ 1$ bill. The third mailing was sent out 5 days after the second mailing and consisted of a postcard thanking buyers for their participation and reminding them to return the survey.

The survey design, including the cover letter, multiple mailings, and token thanks of the enclosed dollar bill, appeared to be very effective at encouraging response. Of the 5250 we sent, 2470 were returned completed or partially completed, for a response rate of $47 \%$.

Response issues: In cases in which the answer to a question was missing but could be easily inferred from a followup question we filled in the answer. For example, if a buyer did not answer whether she had used the Internet but proceeded to detail the types of sites she had visited we filled in that she had used the Internet. We also corrected two inconsistencies in the way surveys were filled out. The first correction concerns a question about the respondent having collected information about the car he or she eventually purchased. We corrected answers for which there were two ways to determine that the answer was erroneous. For example, if a person indicated he had researched zero cars and also spent zero hours doing research online and zero offline, then we did not allow him to be have "collected information about the car he/she eventually purchased." The second correction concerns the question of whether the respondent had in any way used the Internet in conjunction with buying a car. For example, 
some buyers checked off that they did not use the Internet to search for a car but then continued to indicate which websites they had visited for research. In this case we changed the answer on the internet use question to "yes." 1

In survey based research it is normally difficult to assess how respondents and non-respondents differ along relevant dimensions. In our case this assessment is easier: since we have transaction data for respondents and non-respondents alike, we can compare these two groups along any variable we observe in the transaction data. First, we can compare the census-based demographic information associated with the census block groups in which buyers reside. Assuming that these census based measures are representative of individual buyers' demographics, nonrespondents are significantly (at the $5 \%$ level) less likely to be college graduates (27\% vs. $31 \%$ ), more likely to be high school drop-outs (18\% vs. $13.5 \%)$, more likely to be Hispanic or black (20\% and $5 \%$ vs. $16 \%$ and $4 \%$, respectively), have lower household incomes $(\$ 55,000$ vs. $\$ 59,000)$, and own less valuable houses $(\$ 214,000$ vs. $\$ 228,000)$. There is no statistically significant difference between the two groups in the percentage of buyers who are identified as female on the basis of their first name. Second, we can compare how respondents and non-respondents differ with regards to behavioral measures contained in the transaction data. With regards to price - the dependent variable used in this study - there is no significant difference between respondents and non-respondents at the $5 \%$ level. Neither do we find a statistically significant difference in the dealer profitability of purchases by respondents and by non-respondents.

We are not concerned about the demographic differences between respondents and nonrespondents. This is for two reasons. First, the differences do not seem large enough for respondents and non-respondents to differ significantly with respect to our dependent variable (or other transaction-based behavioral measures). Second, in our previous research we have

\footnotetext{
${ }^{1}$ Our conclusions are unaffected by these corrections. To test for robustness, we repeated all specifications in the paper with a dataset from which we dropped the inconsistent 71 survey responses. We also repeated all specifications with a dataset which was left completely unaltered. While the magnitude of coefficients vary slightly between datasets, our substantive findings are unchanged.
} 
found that it is the poorest, least educated buyers who pay most for a car, ceteris paribus. These are precisely the buyers who were least likely to respond to our survey (although the difference in prices paid by these buyers compared to respondents is not large enough to be statistically significant). Thus, since our results rely on between-consumer differences in prices paid due to differences in search and purchase behavior, price differences are likely to be smaller within respondents than within the general population. Consequently, our results are likely to be a conservative lower bound of the true benefits of searching and using the Internet.

Basic survey findings: Seventy-two percent of respondents reported that they used the Internet in some way to help them shop for a new vehicle. The most frequently visited site by buyers who reported using the Internet were manufacturer websites (70\%). Internet consumers also frequently visited informational websites such as consumerreports.com or kbb.com (63\%), followed by online buying services such as Autobytel.com or Carsdirect.com (56\%) and individual dealer websites (31\%). Only $6 \%$ of buyers who used the Internet collected information via chat rooms or bulletin boards. $78 \%$ of buyers who had used the Internet responded that they had explicitly mentioned that fact to the dealer.

Internet users report having collected information on more car types than buyers who did not use the Internet. The median buyer who used the Internet collected information for 2-3 cars whereas the median offline buyer only collected information for 1 car. Most strikingly, only $52 \%$ of buyers who did not use the Internet said that they had collected information (from any source) specifically on the vehicle they ended up buying. This contrasts with $95 \%$ for buyers who used the Internet. Across both groups the average is $82 \%$.

\subsection{Transaction data}

DSA collects transaction data from a sample of dealers in the major metropolitan areas in the US. These data include some customer information, the make, model and trim level of the car, financing information, trade-in information, dealer-added extras, and the profitability of the 
transaction to the dealership.

The price observed in the dataset is the price that the customer pays for the vehicle including factory installed accessories and options and the dealer-installed accessories contracted for at the time of sale that contribute to the resale value of the car. ${ }^{2}$ The Price variable we use as the dependent variable is this price, minus the ManufacturerRebate, if any, given directly to the consumer, and minus what is known as the TradeInOverAllowance. TradeInOverAllowance is the difference between the trade-in price paid by the dealer to the consumer and the wholesale value of the specific trade-in vehicle (as estimated by the dealer). We adjust for this amount to account for the possibility, for example, that a dealer may offer a consumer a low price for the new car because the dealer is profiting from the trade-in.

We control for car fixed effects according to the definition of a "car" above. While our car fixed effects will control for many of the factors that contribute to the price of a car, it will not control for the factory- and dealer-installed options which vary within trim level. The price we observe covers such options but we do not observe what options the car actually has. In order to control for price differences attributable to options, we include as an explanatory variable the percent deviation of the dealer's cost of purchasing the vehicle from the average vehicle cost of that car in the dataset. This percent deviation, called VehicleCost will be positive when the car has an unobserved option (for example a CD player) and is therefore relatively expensive compared to other examples of the same car. Our measure of price also takes into account any variation in holdback and transportation charges.

To control for time variation in prices, we define a dummy EndOfMonth that equals 1 if the car was sold within the last 5 days of the month. This dummy accounts for the fact that sales people get bonuses when they fulfill monthly sales quotas, changing their incentive to hold out for a high price. A dummy variable WeekEnd specifies whether the car was purchased on a

\footnotetext{
${ }^{2}$ Dealer-installed accessories that contribute to the resale value include items such as upgraded tires or a sound system, but would exclude options such as undercoating or waxing.
} 
Saturday or Sunday to control for whether consumers who buy cars on weekends are different from other consumers in ways that are otherwise unobserved. In addition, we include a dummy for the second month in our 2-month sample period to control for other seasonal effects.

We control for the competitiveness of each dealer's market. For each dealership we count the number of dealerships with the same nameplate that fall in a zip code that is within a 10 mile radius of the zip code of the focal dealership. We take into account cases where one owner owns several franchises in close proximity so that our measure counts only the number of separately-controlled entities.

We also supplement the demographic information from the survey with census data that DSA matches with the buyer's address from the transaction record. The data is on the level of a "block group," which makes up about one fourth of the area and population of a census tract. On average, block groups have about 1100 people in them. Finally, we control for whether the car was sold in Northern or Southern California.

Combining the two datasets results in 1,436 observations. This is smaller than the number of returned surveys because of missing information in the transaction dataset and some only partially completed surveys.

\section{Results}

We now proceed to using the direct measures of search behavior and consumer characteristics to investigate how the Internet lowers negotiated prices in car retailing. Our dependent variable is Price as defined in the data section. In order to provide the appropriate baseline for the price of the car, we use a standard hedonic regression of log price. We work in logs because the price effect of many of the attributes of the car, such as being sold in Northern California or in May, are likely to be better modeled as a percentage of the car's value than a fixed dollar increment. We estimate the following specification: 


$$
\ln \left(\text { Price }_{i}\right)=X_{i} \alpha+D_{i} \beta+S_{i} \gamma+\epsilon_{i}
$$

The $X$ matrix is composed of transaction and car variables: car, month, and region fixed effects, car costs, and controls for whether the car was purchased at the end of month or the weekend, and whether the buyer traded in a vehicle. The $D$ matrix contains demographic characteristics of the buyer and her census block group (see Table 1 in the appendix for summary statistics). We use demographic information on gender, age, education, income, and race from the survey. We use information on house ownership, median house value, and type of occupation in the census block group in which the buyer resides. We control for these demographic variables because we know from Scott Morton, Zettelmeyer, and Silva-Risso (2003) that they are related to negotiated car prices. In addition, these variables are also correlated with the search and purchasing behavior we intend to analyze in this paper; their inclusion is thus critical to avoid bias in the coefficients of interest. ${ }^{3}$ To this basic specification we add a matrix $S$ which contains survey responses that indicate the search behavior and Internet use of a buyer.

We begin our investigation of the role of the Internet by including an indicator to the specification which is one if a buyer answered "yes" to the question "Did you use the Internet in any way to help you shop for a new vehicle? (e.g. to research vehicles, find a dealer, etc.)." We refer to this indicator as InternetUse (see column 1 in Table 2). We find that buyers who reported having used the Internet in any way to help them shop for a new vehicle pay on average $1.16 \%$ less than other buyers ( $\mathrm{p}$-value $<0.001$ ).

While this describes the average difference in the prices paid by Internet users and nonusers, respectively, this average likely does not measure the expected return to a customer of

\footnotetext{
${ }^{3}$ For example, education is good predictor of Internet usage. Only $37 \%$ of buyers who reported not to have a high school degree used the Internet. This is in contrast to $81 \%$ of buyers with a college degree or higher. Also, $87 \%$ percent of buyers with income above $\$ 150,000$ but only $47 \%$ of buyers with income between $\$ 20,000$ and $\$ 29,999$ reported using the Internet for car buying. We will not discuss the estimated coefficients on the demographics in this paper because they are not the focus of the study. The interested reader is referred to Scott Morton, Zettelmeyer, and Silva-Risso (2003) for a detailed analysis of the effects of demographics on the price of a new car. For another approach on the effect of demographics on bargaining outcomes see Chen, Yang, and Zhao (2003).
} 
deciding to use the Internet. The reason is that the average effect on price likely includes effects caused by unobserved customer traits (such as being a "smart shopper") which happen to be correlated with using the Internet.

\section{Is the Internet effect driven by unobserved differences between online and offline consumers?}

In order to estimate the "treatment effect" of using the Internet, in this section we run the same specification as above, but this time we control for consumer types. We are able to (imperfectly) measure normally "unobserved" consumer types by asking our consumers particular questions on the survey. While controlling for these measures cannot rule out that some of the Internet effect remains driven by unobserved differences between consumers, we measure consumers characteristics which we ex-ante believe best predict consumers' underlying propensity to search for purchase-relevant information and to use the Internet. ${ }^{4}$

We ask consumers to rate their agreement or disagreement with a list of statements to get a measure of three consumer traits. ${ }^{5}$ These traits are (1) whether a consumer has a high willingness to search, (2) whether a consumer is a car enthusiast, and (3) whether a consumer has a high disutility of bargaining. To get answers that are reliable and as comparable as possible across respondents we ask survey participants questions about their behavior or attitudes, not about the traits directly. For example, we are interested in the "car enthusiast" trait to control for whether a consumer knows a lot about cars, even if they did little or no search for their car purchase. We could have asked a survey participant to agree or disagree with the statement "I am a car enthusiast," thereby leaving it up the respondent to decide what a car enthusiast is. Instead, we get more consistent answers by asking "I read car- and/or

\footnotetext{
${ }^{4}$ At then end of section 4 we show that these consumer characteristics are indeed correlated with Internet use. This is also true for some other independent variables of interest (not reported). Since our measures of consumer characteristics are also related to the prices paid by consumers, this shows the importance of controlling for these characteristics in subsequent specifications in order to avoid biased estimates.

${ }^{5}$ These measures were chosen based on our prior research findings, and discussions with car and internet industry experts.
} 
truck-enthusiast magazines regularly" and "I tend to visit dealers whenever a new model is introduced." 6 Similarly, we get at consumers' willingness to search with statements such as "I do a lot of price comparison when making large purchases," "I am the kind of person who gathers as much information as possible before visiting car dealers," and "I frequently use the Internet to obtain information about products I am interested in." Finally, to assess whether a consumer derives a high disutility from the bargaining process we present consumers with the statements "I am afraid that I will be taken advantage of by a dealer when negotiating the price of a new car," and "It is hard for me to find time to shop for a new vehicle." We assume that consumers who feel very vulnerable will dislike bargaining more than consumers who do not feel vulnerable. The response to the second statement measures the consumer's assessment of her opportunity cost of being engaged in a bargaining interaction. ${ }^{7}$

To investigate how our survey questions map into the three consumer traits they are intended to measure we employ a factor analysis. Three factors have eigenvalues above 1 and their interpretation corresponds exactly to our three consumer traits. The first factor-with high factor loadings on the three "willingness to search" questions ${ }^{8}$ — has an eigenvalue of 1.99 and explains $28 \%$ of the variation in the seven items. The second factor-with high factor loadings on the two "car enthusiast" questions - has an eigenvalue of 1.51 and explains $22 \%$ of the variation in the seven items. The third factor - with high factor loadings on the two "bar-

\footnotetext{
${ }^{6}$ Note that these questions may not entirely overcome our concerns associated with asking consumers questions with vague terms. In particular, some of our questions involve an implicit norm that may differ between, for example, Internet-based and other buyers. This is a limitation of our survey which we cannot overcome at this time.

${ }^{7}$ The consumer traits we construct are based in part on a consumer's own assessment of his or her bargaining ability. These assessments are made 6-12 weeks after the consumers purchased a car. If consumers infer their bargaining ability from the price they obtained for this particular vehicle, there could be an endogeneity between prices and consumer traits. If this is the case, too much of the price effect will be attributed to consumer traits and too little to other factors, such as information search. While this endogeneity is of concern, since the primary purpose of the consumer traits is to function as control variables, we believe such endogeneity biases the results against our main findings.

${ }^{8}$ The rotated factor loadings (varimax rotation) for the first factor are 0.82 for DoPriceComparisons, 0.72 for InternetForInfo, and 0.85 for GatherMuchInfo. For the second factor, corresponding to "car enthusiast," the factor loadings are 0.85 for ReadCarMagazine, and 0.84 for VisitDealerForFun. For the third factor, corresponding to "bargaining disutility," the factor loadings are 0.73 for AfraidTakenAdvantage, and 0.78 for NoTimeToShop.
} 
gaining disutility" questions - has an eigenvalue of 1.09 and explains $16 \%$ of the variation in the seven items. The reliability of the measures is as follows: Cronbach's alpha for the three "willingness to search" questions is 0.7 ; the correlation coefficient for the two two-question scales is 0.45 (p-value $<0.001$ ) for "willingness to search" and 0.18 (p-value $<0.001$ ) for "bargaining disutility."

We begin with specifications which include the answers to the individual consumer trait questions directly in the regression (later, in section 3.2 we will use the factors). We repeat the specification in column 1 of Table 2, adding these measures of "unobserved" consumer traits. The coefficient on InternetUse decreases from -1.16 to -0.98 ( $\mathrm{p}$-value 0.01 , see column 2 in Table 2). Consumer traits are related to price as follows: buyers who were more afraid of being taken advantage of by the dealer pay more, suggesting that they had reason to be afraid. Consumers who agree more with the statement "I do a lot of price comparison when making large purchases" pay less (p-value 0.10). Other consumer trait variables are not significantly different from zero. This reflects one consequence of our approach to include all consumer trait variables in the regression. Since several of the questions are, by design, quite similar they may be only jointly significant. Hence we test the hypothesis that the subset of variables which measure each consumer trait are jointly zero. We reject the hypothesis that the variables measuring consumers' disutility of bargaining (AfraidTakenAdvantage, NoTimeToShop) are jointly zero (p-value 0.001). We also reject the hypothesis that the variables measuring consumers' willingness to search (DoPriceComparisons, InternetForInfo, GatherMuchInfo) are jointly zero (p-value 0.05). We cannot reject the hypothesis that the variables measuring whether a consumer is a car enthusiast (ReadCarMagazine, VisitDealerForFun) are zero (p-value 0.43).

We conclude that the Internet effect is unlikely to result from differences between online and offline consumers in their demographics, their bargaining disutility, their willingness to search, or their knowledge about cars; buyers who have used the Internet pay approximately 
$1 \%$ less, even after controlling for demographics and (normally unobserved) consumer traits. ${ }^{9}$ This corresponds to $15 \%$ of dealers' average gross profit margin per vehicle.

\section{Does Internet use serve as a signal to dealers?}

While we have shown above that the Internet effect seems not to be the result of measurable differences between online and offline consumers, it could still be that the Internet discount results from the perception of dealers that Internet consumers are different. We can analyze this question because we asked consumers whether they had mentioned to the dealer that they used the Internet to do research. If the Internet saves consumers money because dealers assume that consumers who used the Internet are different from "regular" consumers, we should find that the Internet effect should differ between consumers who told the dealer they had used the Internet and consumers who did not. ${ }^{10}$ No consumer in our sample reported telling the dealer that they had used the Internet when, in fact, they had not. We repeat the specification in column 2 of Table 2 an indicator variable ToldDealer which is one if a buyer who used the Internet told that dealer that she used the Internet to do research (unreported). We cannot reject the hypothesis that consumers who used the Internet and told the dealer that they had done so paid on average the same price for a new car as consumers who did not tell the dealer about their Internet use (the coefficient on ToldDealer is 0.14 , p-value 0.70 ).

Based on the results of this and the previous discussion we conclude that, based on the survey measures at our disposal, the Internet effect is unlikely to result from actual or dealerperceived differences between online and offline consumers. We are now interested in determining the mechanism by which the Internet lowers the prices paid by consumers.

\footnotetext{
${ }^{9}$ Another way to control for selection would be to instrument for Internet use. Regrettably, it is very difficult to find instruments that are correlated with Internet use and uncorrelated with the prices consumers pay for cars. This is because prices are individually negotiated and thus a function of consumer characteristics which are also likely to predict Internet use. Hence, it is very difficult to argue that there are measures that could be used to predict Internet use in the first-step selection equation, but should be excluded from the price equation. This is why we have chosen the alternative "selection on observables" approach by eliciting normally unobservable consumer characteristics through a survey instrument.

${ }^{10}$ This argument is not valid if dealers can tell whether a consumers used the Internet, irrespective of whether consumers inform the dealer.
} 


\subsection{The role of the Internet}

In the results so far, we have shown that Internet usage leads to prices that are lower by about $1 \%$ and that this is not, insofar as we can tell, because Internet users and non-users differ on observable demographic characteristics or on individual traits which our survey allows us to observe. The aim of this paper, however, goes beyond showing that Internet usage does indeed have a "treatment effect." Our aim is to "unpack" this treatment effect - to understand what it is about what consumers are doing online that leads to lower prices. We first consider the effect the Internet has on prices by aiding consumers in obtaining information.

Does the Internet lower prices by facilitate purchase-relevant information search?

Our aim in this subsection is to estimate how much of the effect of InternetUse on prices is attributable to a consumer being better informed. To do so we make use of the fact that in the survey we ask whether a consumer obtained information about the specific vehicle she eventually purchased. This enables us to observe whether a consumer is informed independently of whether she used the Internet. This is because Informed includes both consumers who gathered information entirely offline, and consumers who used the Internet, but not to obtain information about the specific car they purchased. By comparing the effect of Informed with the effect of InternetUse we can get some sense of how much of the Internet usage effect on price is due to being better informed.

We begin with a specification in which - instead of InternetUse - we include the indicator Informed for whether the buyer collected information specific to the vehicle that she ended up purchasing (see column 3 of Table 2). We find that buyers who reported having collected information for the type of car they eventually purchased pay on average $0.74 \%$ less than other buyers (p-value 0.06). This is somewhat smaller than the coefficient of $0.98 \%$ for InternetUse. In an unreported specification with both variables, Informed becomes insignificant (p-value 0.26) while the InternetUse coefficient changes to -0.81 (p-value 0.045). The similar effect of 
the two variables and a high and significant correlation coefficient of 0.5 suggests that becoming better informed is an important part of the advantage of using the Internet.

\section{How is Internet information helping buyers?}

Having found that information is an important part of how the Internet helps consumers in negotiating lower prices, we would like to know how the information is helping. In particular, we consider two possible hypotheses. First, consumers could be benefitting from using the Internet because doing so provides them with information that helps them better negotiate with a dealer. Second, consumers could be benefitting from using the Internet because doing so helps them find low-price dealers.

We begin by investigating what kind of information matters most in price negotiations. We asked respondents what information they researched on the Internet, including "which car to purchase," "which dealers to visit or buy from," "dealer cost (invoice/hold-back)," or the "fair price or market value." We find that the only piece of information that affects transaction price is the invoice price of the car. Consumers who have collected information about the invoice price of the car they wish to buy pay on average $0.61 \%$ less than other buyers (p-value 0.04, see column 4 in Table 2). ${ }^{11}$ Since the invoice price of a dealer is closely related to the dealer's reservation price for a specific vehicle, our result implies that, on average, consumers who have better information about a dealer's reservation price will do better in price negotiations than consumers who are uninformed. This finding is consistent with predictions from the gametheoretic literature on bargaining with incomplete information (see Chatterjee and Samuelson (1983) for a static model, Fudenberg, Levine, and Tirole (1985) and Gul, Sonnenschein, and Wilson (1986) for dynamic buyer-offer models, and Ausubel and Deneckere (1998) for a dynamic alternating-offer model which generate this prediction). ${ }^{12}$ Overall, consumers seem to

\footnotetext{
${ }^{11}$ This result is not due to collinearity between the four information variables. We obtain the same result if we run four separate specifications, each of which contains all controls but only one of the four information variables at a time (not reported).

${ }^{12}$ See Scott Morton, Zettelmeyer, and Silva-Risso (2004) for a more detailed literature review.
} 
be benefitting from using the Internet because it provides them with information that helps them better negotiate with a dealer.

In contrast, we can find no evidence that consumers are benefitting from using the Internet because doing so helps them find low-price dealers. For many non-car products, the Internet makes it possible to compare prices offered by competing retailers either by checking multiple sites or with a price comparison site such as MySimon.com. Since dealer franchise laws require cars to be sold through dealerships and since almost all dealerships engage in price negotiation, this kind of direct price comparison is not possible for cars. However, we can observe in our data that some dealers do offer consistently lower prices than others. While it is possible that consumers may be able to learn this information, for example, in an online discussion forum or by inference from a dealer's own website, we find no evidence in our data that this is occurring to any significant degree.

We can see this in several specifications. First, in column 4 in Table 2, a response indicating that a consumers has collected information on "which dealers to visit or buy from" has no statistically significant effect on the price. Another way of testing whether the Internet effect is due to consumers finding low-price dealerships is to add dealer fixed effects to the core specification in column 2 in Table 2. In this unreported regression, the estimated coefficient on the InternetUse variable is identified by within-dealer variation in whether consumers are informed or not. Since identification in this specification does not rely on differences in average price levels between dealers, the results cannot be due to consumers searching for low-price dealerships. The coefficient on InternetUse remains significant and negative at $-0.81 \%$ (p-value $0.04)$.

A third way of investigating whether the Internet is used to gather information that helps consumers find low-price dealers is to test whether InternetUse substitutes for search among dealers. We asked buyers how many other dealerships they visited. If we add the number of visited dealers to the core specification in column 2 in Table 2, each increase in response scale 
category for the number of visited dealers decreases price by $0.34 \%$ (p-value 0.02 , regression unreported). Most importantly, the coefficient on InternetUse remains significant and changes little $(-0.85 \%, \mathrm{p}$-value 0.03$)$. The fact that each variable appears to influence negotiated prices when both are included in the regression suggests that dealer search and InternetUse are not performing exactly the same role.

The results in this subsection suggests that Internet information helps consumers by enabling them to negotiate a low price at a given dealership. However, Internet information seems not to help car buyers find low-price dealerships.

We now want to know whether the Internet serves any additional role in lowering prices for consumers. We explore this question by distinguishing among the different ways in which consumers can use the Internet. In particular, we distinguish between manufacturer websites, individual dealer websites, online buying services, informational websites, and chat rooms. For each type of online source we construct an indicator that is one if a buyer used that source of information. Column 5 in Table 2 reports a specification that contains \#Dealers Visited, and the indicators for how the Internet was used. We find that online buying services are the only type of online site which is associated with lower price. ${ }^{13}$ The coefficient is -0.90 and highly significant (p-value 0.001). This leads us to investigate the role of online buying services next.

\section{How are online buying services helping buyers?}

Online buying services and manufacturer websites differ from other online sources in that they go beyond providing information to consumers. All online buying services and many manufacturer websites allow consumers to request a quote from a dealer. The dealer typically calls or e-mails the referred consumer within 24-48 hours with a price quote. A consumer can ask for a price quote in a few seconds on a website, and receive it in his or her home the next day. This raises the question of whether some of the savings from using the Internet

\footnotetext{
${ }^{13}$ This result is not due to collinearity between the five variables describing how consumers use the Internet. We obtain the same result if we run five separate specifications, each of which contains all controls but only one of the five information variables at a time (not reported).
} 
could be driven by a mechanism that is distinct from informing customers, namely the referral process. To investigate the effect of utilizing the referral process, we add to the basic Internet specification with \#Dealers Visited an indicator that is one if a consumers answered "yes" to the question "Did you submit a formal request to any online buying service (e.g. Autobytel.com, Carpoint.com, Autoweb.com) to be referred to one of the site's affiliated dealers?" We also add an indicator that is one if a consumers answered "yes" to the equivalent question for referrals from manufacturer websites.

We find that submitting a referral to an independent online buying service is associated with $0.72 \%$ lower prices, in addition to the savings of $0.76 \%$ (p-value 0.05 ) associated with using the Internet (see column 6 in Table 2). Manufacturer referrals, in contrast, have no effect on price.

This result is very important because it indicates that there is some important aspect of the business model of independent referral sites that drives the difference. The major difference between a referral from an online buying service and from a manufacturer is that the manufacturer refers consumers to the closest dealer selected from the entirety of its dealerships while online buying services sign contracts with only a subset of dealers. For example, out of the approximately 22,000 dealers in the US, Autobytel.com in the first quarter of 2001 contracted with 5,000 dealerships. Online buying services assign dealers exclusive territories, and refer all customers within that territory who submit a purchase referral for the dealer's nameplate to that dealer. Since only a subset of dealers are affiliated with a given online buying service, this dealer's exclusive territory will be larger than the territory in which it is the closest dealer of that nameplate. This implies that referrals from an online buying service will more often be incremental to the dealership's regular customers than referrals from manufacturers. Manufacturers will refer to dealers only customers for whom the dealer is already the closest dealer of that nameplate. Provided the incremental stream of customers generated by the online buying service is valuable to the dealership, the dealership has an incentive to quote prices low enough 
to convert a substantial number of referrals into sales. This is because online buying services monitor the percentage of referrals that result in a sale, and if the percentage is too low, the dealer may be terminated and replaced by another dealer in that area. The implied threat is not only that incremental sales get lost, but also that the replacement dealer will then "steal" some of the dealership's own consumers. Such a threat is not available to manufacturers.

This argument bears resemblance to that of Klein and Murphy (1988) and Klein (1995) on contractual provisions in franchising. Klein (1995) argues that three elements are necessary for the loss of future rents to be a credible threat for a franchisee: (1) the contract between the franchisor and franchisee must leave downstream rents for the franchisee, (2) the franchisor must be allowed to monitor the performance of the franchisee, and (3) the franchisor must be able to easily drop the franchisee. These condition are similar to what we observe for the contracts between online buying services and their affiliated dealers: (1) Dealers are given exclusive "online territories" which are substantially larger than their offline territories, thereby creating incremental profits for dealers, (2) online buying services monitor the performance of dealers with customer satisfaction surveys, and (3) online buying services can easily drop dealerships from their roster. This interpretation of the role of exclusive territories is different from the one hypothesized by Chen, Iyer, and Padmanabhan (2002). In their paper online buying services grant exclusivity to dealers to avoid Bertrand-type competition among dealers. In contrast, our argument and that of Klein (1995) suggests that exclusivity is granted in order to ensure dealer performance, which in this context means offering lower prices to consumers. In a sense, independent online buying services bargain with dealers on behalf of a large group of consumers, although that group is not yet formed. With this interpretation our result is also consistent with the theoretical predictions of Snyder (1998) who shows why groups of buyers should expect to pay lower prices to a seller than individual buyers.

In summary, buyers who use the Internet to shop for a car seem to be paying lower prices for two distinct reasons. First, they become on average better informed than other buyers. 
This information gives consumers better knowledge of of a dealer's opportunity cost, which tends to lower the transaction price the consumer pays. Second, buyers seem to be able to take advantage of any pressure that online buying services exert on dealers through their ability to direct customers among dealers. The total Internet effect is $1.5 \%$ of the purchase price, or $22 \%$ of dealers's average gross profit margin. ${ }^{14}$

\subsection{Does the Internet benefit all consumers equally?}

Next, we investigate whether the information and referral effects accrue to all buyers equally. In particular we are interested in whether the Internet "levels the playing field" by improving outcomes by more for individuals who would do worse without the Internet. In this paper, we can examine this question because in our survey we ask explicitly about indicators that an individual is at a bargaining disadvantage and we observe a range of car-purchase related Internet activities.

In the survey, we ask respondents to rate their agreement with the statements "I am afraid that I will be taken advantage of by a dealer when negotiating the price of a new car" and "It is hard for me to find time to shop for a car." We believe there are a number of characteristics that might lead an individual to strongly agree with the first statement, including aversion to conflict, dislike of stressful situations, or anxiety in high-pressure environments. Instead of trying to assess these elements independently, we ask for a summary assessment that describes the consumer's level of apprehension about the bargaining process. In addition, we also ask whether individuals have a time constraint that would make participation in extended negotiations costly for them. We expect that both aspects will make the bargaining process unattractive and lead to less desirable outcomes for consumers.

\footnotetext{
${ }^{14}$ We provide one additional piece of evidence to show that the "Internet effect" can be broken into a referral and an informational component. In a regression that controls for the referral effect, the variable InternetUse and the variable Informed are almost interchangeable (see column 6 and 7 in Table 2). The InternetUse coefficient is estimated at -0.76 in the first column (p-value 0.05 ). The second specification no longer includes InternetUse but yields a coefficient estimate of -0.67 for Informed ( $\mathrm{p}$-value 0.09 ). The effect of a referral is similar in the two specifications.
} 
We use the responses to these statements to create an indicator variable, DislikeBargaining, which is one if a buyer derives a higher disutility from the bargaining process than the median buyer. We derive this indicator using two different approaches. In our first approach we construct a variable which is the sum of the normalized values of the responses to the two statements. ${ }^{15}$ We then create an indicator which is one for a buyer with a higher value on this variable than the median buyer. We run a specification in which we include DislikeBargaining on its own and also interacted with both InternetUse and OBSReferral (see column 1 in Table 3). We find that consumers who DislikeBargaining pay $2.1 \%$ more than consumers who do not ( $\mathrm{p}$-value $<0.001)$. We also find that consumers who obtained a referral from an online buying service pay $0.83 \%$ less than those who do not (p-value 0.07 ); these savings accrue equally to buyers who do and do not DislikeBargaining. (The DislikeBargaining-OBSReferral interaction term is statistically zero.) Using the Internet, however, only benefits consumers who dislike bargaining (by 1.7\%, p-value 0.01); consumers who like to bargain (presumably because they are good bargainers) do not benefit from using the Internet other than by obtaining a referral.

To ensure the robustness of these findings we use the factor BargainingDisutility from the factor analysis on page 15 to derive our indicator variable. We redefine our indicator to be one if a buyer derives a higher BargainingDisutility than the median buyer.

We repeat the previous specification, however, instead of including the consumer trait measures directly, we make use of the factors WillingnessToSearch and CarEnthusiast to control for consumer types. The results are similar to the previous specification (see column 2 in Table 3). We find that consumers who DislikeBargaining pay $2.0 \%$ more than consumers who do not. We also find that consumers who obtained a request from an online buying service pay $0.74 \%$ less than those who do not (p-value 0.10 ); again these savings accrue equally to buyers

\footnotetext{
${ }^{15}$ For each variable we calculate the mean and standard deviation over all respondents. Then we normalize the answer for each individual by subtracting the mean and dividing by the standard deviation.
} 
who do and do not DislikeBargaining. As before we find that using the Internet only benefits consumers who dislike bargaining (by 1.5\%); consumers who like to bargain or have the time to do so do not benefit from using the Internet other than by obtaining a referral. The sum of the marginal Internet effects is shown in the following table.

\begin{tabular}{|l||c|c|}
\hline & Likes bargaining & Dislikes bargaining \\
\hline \hline $\begin{array}{l}\text { Used Internet for information } \\
\text { (but did not request referral) }\end{array}$ & $0 \%$ & $-1.5 \%$ \\
\hline In addition, requested referral & $-0.7 \%$ & $-0.7 \%$ \\
\hline \hline Total Internet effect & $-0.7 \%$ & $-2.2 \%$ \\
\hline
\end{tabular}

Our first result of this section is that buyers who dislike the bargaining process benefit much more from being informed. This suggests that the effect of the Internet's information provision role is, at least in car buying, to move consumers towards a more level playing field in terms of bargaining ability. Indeed, individuals who do not dislike bargaining do not appear to benefit at all from being better informed by the Internet. One can argue that, colloquially, this is the very definition of being a good bargainer: to be able to do well without knowing much about one's own and the other party's outside options. ${ }^{16}$

The second key result is that the benefits of requesting a referral accrue equally to all buyers. We have argued in section 3.1 that a referral from an online buying service lowers prices at a dealer because of the implicit threat to direct customers to the dealer's competitors. Consistent with our findings, if this threat operates, it seems reasonable that it should apply uniformly across consumers.

It is important to note that our result that buyers who like the bargaining process do not benefit from being informed is not specific to the Internet specification: we repeat the basic Informed specification from column 7 of Table 2 with the DislikeBargaining dummy and the interaction of the dummy with Informed. ${ }^{17}$ We find that consumers who DislikeBargaining pay $2.6 \%$ more than consumers who do not (see column 3 in Table 3 ). We find the same qualitative

\footnotetext{
${ }^{16}$ For example, being able to negotiate a salary raise after having received a competing job offer is not a sign of good bargaining skills. However, negotiating a raise without such an offer may very well be.

${ }^{17}$ We construct the dummy according to the first approach in this subsection.
} 
result as in our two Internet specifications, namely that the benefits of being Informed accrues only to consumers who dislike bargaining (by $2.0 \%$ ).

Finally, if a subset of consumers gain disproportionately from using the Internet to buy a car, economic theory suggests that this group should be disproportionately likely to use the Internet. Our final specification in Table 3 is a probit that relates a buyer's decision to use the Internet the consumer trait measures constructed in the factor analysis. We find that buyers with a higher disutility from the bargaining process are more likely to use the Internet.

\section{Conclusion}

In this paper we use direct measures of search behavior and consumer characteristics in the car industry to investigate how the Internet affects negotiated prices in car retailing. We match transaction data on 1,500 car purchases in California with the responses to a survey which asks buyers detailed questions about their Internet usage, their attitudes towards information search and bargaining, and their demographics.

Our survey data enable us to control directly, at an individual level, for heterogeneity in attitudes towards search and bargaining disutility. While these controls cannot fully rule out selection bias, they increase our confidence that the price effects are not an artifact of differences in unobserved characteristics between people who use the Internet and those who do not.

We show that the Internet lowers prices for two distinct reasons. First, the Internet informs consumers. The information that seems to be most valuable to consumers is the invoice price of the dealer; it enables them to negotiate a low price at a given dealership. Internet information seems not to help consumers find low-price dealerships. In particular, the Internet does not substitute for searching at multiple dealers. Nor does searching at multiple dealers substitute for being better informed.

Second, the incentives provided by online buying services' contracts with dealerships help 
consumers obtain lower prices through a referral process. Referrals from manufacturer websites do not lower prices. We believe that online buying services are more effective because, unlike manufacturers, they can exert pressure on dealers by directing incremental business to affiliated - and away from unaffiliated - dealerships. The magnitude of the combined information and referral effect of the Internet is $1.5 \%$ of the purchase price, or $22 \%$ of dealers's average gross profit margin.

We find that the benefit of gathering information differs by consumer type. While buyers with a high disutility of bargaining pay $1.5 \%$ less when they have collected information on the specific car they eventually purchase, buyers who like the bargaining process do not benefit from such information.

The point estimate of the combined information and referral price effects is close to the estimate of Zettelmeyer, Scott Morton, and Silva-Risso (2004). They found that, after controlling for selection, Autobytel.com lowered prices by 2.2\%. Since Autobytel.com is a major online buying service, we can compare this estimate with the sum of our InternetUse and OBSReferral coefficients in the last subsection, $1.5 \%$, or with the estimate of 2.2 to $2.5 \%$ for consumers with a high disutility from bargaining. The similarity of the coefficient estimates is remarkable given that Zettelmeyer, Scott Morton, and Silva-Risso (2004) use data from 1999, the height of the Internet boom and a time of experimentation by both consumers and retailers. In contrast, the data in this paper are from April and May of 2002, when the Internet had become more mainstream.

More generally, the results in this paper suggest that the decisions consumers make to use the Internet to gather information and to use the negotiating clout of an online buying service have a real effect on the prices paid by these consumers. The results speak both to the significance of the Internet in making information more easily available, and also to the potential of Internet institutions to affect the distribution of surplus even in established offline industries like auto retailing. 


\section{References}

Ausubel, L. M., And R. J. Deneckere (1998): "Bargaining and Forward Induction," mimeo, University of Maryland University of Wisconsin-Madison.

Brown, J. R., And A. Goolsbee (2002): "Does the Internet Make Markets More Competitive? Evidence from the Life Insurance Industry," Journal of Political Economy, 110(5), $481-507$.

Chatterjee, K., and L. Samuelson (1983): "Bargaining under Incomplete Information," Operations Research, 31(5), 835-851.

Chen, Y., G. Iyer, and V. Padmanabhan (2002): "Referral Infomediaries," Marketing Science, 21(4), 23-45.

Chen, Y., S. Yang, and Y. Zhao (2003): "A Structural Approach to Modeling Negotiated Prices of Automobiles," New York University, New York, NY.

FudenberG, D., D. K. Levine, and J. Tirole (1985): "Infinite-Horizon Models of Bargaining with One-Sided Incomplete Information," in Game Theoretic Models of Bargaining, ed. by A. Roth. Cambridge University Press, Cambridge, England.

Furse, D. H., G. N. Punj, and D. W. Stewart (1984): "Typologies of Individual Search Strategies Among Purchasers of New Automobiles," Journal of Consumer Research, 10, $417-431$.

Gul, F., H. Sonnenschein, and R. Wilson (1986): "Foundations of Dynamic Monopoly and the Coase Conjecture," Journal of Economic Theory, 39, 155-190.

Klein, B. (1995): "The Economics of Franchise Contracts," Journal of Corporate Finance: Contracting, Governance and Organization, 2, 9-37. 
Klein, B., And K. MurPhy (1988): "Vertical Restraints as Contractual Enforcement Mechanisms," Journal of Law and Economics, 31, 265-297.

Klein, L. R., And G. T. Ford (2001): "Consumer Search for Information in the Digital Age: An Empirical Study of Pre-Purchase Search for Automobiles," mimeo, Rice Univeristy, Houston, TX.

Moorthy, S., B. T. Ratchford, and D. TAlukdar (1997): "Consumer Information Search Revisited: Theory and Empirical Evidence," Journal of Consumer Research, 23(4), 263-277.

Ratchford, B., ANd N. SRinivasan (1993): "An Empirical Investigation of Returns to Search," Marketing Science, 12(1), 73-87.

Ratchford, B. T., D. Talukdar, and M.-S. Lee (2003): "The Impact of the Internet on Information Search for Automobiles," Journal of Marketing Research, 40(2), 193-209.

Scott Morton, F., F. Zettelmeyer, and J. Silva-Risso (2001): "Internet Car Retailing," Journal of Industrial Economics, 49(4), 501-520.

(2003): "Consumer Information and Discrimination: Does the Internet Affect the Pricing of New Cars to Women and Minorities?," Quantitative Marketing and Economics, $1(1), 65-92$.

(2004): "A Test of Bargaining Theory in the Auto Retailing Industry," Discussion paper, UC Berkeley.

SNyDER, C. M. (1998): "Why do larger buyers pay lower prices? Intense supplier competition," Economic Letters, 58, 205-209.

Zettelmeyer, F., F. Scott Morton, and J. Silva-Risso (2004): "Cowboys or Cowards: Why are Internet car prices lower?," Discussion paper, Berkeley, CA. 
Table 1: Summary Statistics ${ }^{\dagger}$

\begin{tabular}{|c|c|c|c|c|c|}
\hline & Obs & Mean & Std. Dev. & Min & $\operatorname{Max}$ \\
\hline \multicolumn{6}{|c|}{ Demographic Variables From Survey } \\
\hline Age & 1436 & 3.03 & 0.91 & 1.00 & 5.00 \\
\hline Education & 1436 & 4.82 & 1.44 & 1.00 & 7.00 \\
\hline Income & 1436 & 5.18 & 2.19 & 1.00 & 10.00 \\
\hline Black & 1436 & 0.03 & 0.18 & 0.00 & 1.00 \\
\hline Hispanic & 1436 & 0.20 & 0.40 & 0.00 & 1.00 \\
\hline Female & 1436 & 0.40 & 0.49 & 0.00 & 1.00 \\
\hline \multicolumn{6}{|c|}{ Demographic Variables From Census } \\
\hline \%HouseOwnership & 1436 & 0.67 & 0.24 & 0.01 & 1.00 \\
\hline MedianHouseValue & 1436 & 2.28 & 1.06 & 0.19 & 5.00 \\
\hline \%Professional & 1436 & 0.16 & 0.08 & 0.00 & 0.62 \\
\hline$\%$ Executives & 1436 & 0.17 & 0.08 & 0.00 & 1.00 \\
\hline$\%$ BlueCollar & 1436 & 0.27 & 0.16 & 0.00 & 0.91 \\
\hline$\%$ Technicians & 1436 & 0.03 & 0.02 & 0.00 & 0.16 \\
\hline \multicolumn{6}{|c|}{ Summary Statistics from Transaction Data } \\
\hline Price & 1436 & 23284.92 & 5499.61 & 9800 & 38750 \\
\hline TradeIn & 1436 & 0.30 & 0.46 & 0.00 & 1.00 \\
\hline EndOfMonth & 1436 & 0.20 & 0.40 & 0.00 & 1.00 \\
\hline Weekend & 1436 & 0.30 & 0.46 & 0.00 & 1.00 \\
\hline Competition & 1436 & 4.50 & 3.06 & 0.00 & 16.00 \\
\hline MonthMay & 1436 & 0.52 & 0.50 & 0.00 & 1.00 \\
\hline SouthernCal & 1436 & 0.62 & 0.48 & 0.00 & 1.00 \\
\hline
\end{tabular}

$\dagger$ Age, education, income represent response categories.

MedianHouseValue in $\$ 100,000$.

Competition: number of dealers of same nameplate in a 10 mile radius of dealership. 
Table 2: Price effects of search and purchasing behavior ${ }^{\dagger}$

\begin{tabular}{|c|c|c|c|c|c|c|c|}
\hline Dep. Var. $\ln$ (price) & (1) & $(2)$ & $(3)$ & $(4)$ & $(5)$ & (6) & $(7)$ \\
\hline InternetUse & $\begin{array}{l}-1.16 \\
(0.32) * *\end{array}$ & $\begin{array}{c}-0.98 \\
(0.39) *\end{array}$ & & & & $\begin{array}{c}-0.76 \\
(0.39)+\end{array}$ & \\
\hline Informed & & & $\begin{array}{c}-0.74 \\
(0.39)+\end{array}$ & & & & $\begin{array}{c}-0.67 \\
(0.39)+\end{array}$ \\
\hline KnowCars & & & & $\begin{array}{c}0.02 \\
(0.31)\end{array}$ & & & \\
\hline KnowDealers & & & & $\begin{array}{c}-0.14 \\
(0.28)\end{array}$ & & & \\
\hline KnowInvoice & & & & $\begin{array}{c}-0.61 \\
(0.30) *\end{array}$ & & & \\
\hline KnowMarketPrice & & & & $\begin{array}{c}-0.04 \\
(0.31)\end{array}$ & & & \\
\hline \#DealersVisited & & & & & $\begin{array}{c}-0.35 \\
(0.14) *\end{array}$ & $\begin{array}{c}-0.31 \\
(0.14) *\end{array}$ & $\begin{array}{c}-0.33 \\
(0.14) *\end{array}$ \\
\hline ManufacturerSite & & & & & $\begin{array}{c}0.13 \\
(0.28)\end{array}$ & & \\
\hline DealerSite & & & & & $\begin{array}{c}-0.19 \\
(0.30)\end{array}$ & & \\
\hline InformationSite & & & & & $\begin{array}{c}-0.12 \\
(0.29)\end{array}$ & & \\
\hline ChatRoom & & & & & $\begin{array}{c}0.73 \\
(0.45)\end{array}$ & & \\
\hline OBSSite & & & & & $\begin{array}{c}-0.90 \\
(0.27) * *\end{array}$ & & \\
\hline OBSReferral & & & & & & $\begin{array}{c}-0.72 \\
(0.28) *\end{array}$ & $\begin{array}{c}-0.80 \\
(0.28) * *\end{array}$ \\
\hline ManufReferral & & & & & & $\begin{array}{c}0.10 \\
(0.34)\end{array}$ & $\begin{array}{c}0.09 \\
(0.34)\end{array}$ \\
\hline AfraidTakenAdv. & & $\begin{array}{c}0.42 \\
(0.13) * *\end{array}$ & $\begin{array}{c}0.42 \\
(0.13) * *\end{array}$ & $\begin{array}{l}0.44 \\
(0.13) * *\end{array}$ & $\begin{array}{c}0.45 \\
(0.13) * *\end{array}$ & $\begin{array}{c}0.43 \\
(0.13) * *\end{array}$ & $\begin{array}{l}0.44 \\
(0.13) * *\end{array}$ \\
\hline NoTimeToShop & & $\begin{array}{c}0.23 \\
(0.15)\end{array}$ & $\begin{array}{c}0.22 \\
(0.15)\end{array}$ & $\begin{array}{c}0.25 \\
(0.15)\end{array}$ & $\begin{array}{c}0.21 \\
(0.15)\end{array}$ & $\begin{array}{c}0.19 \\
(0.15)\end{array}$ & $\begin{array}{c}0.18 \\
(0.15)\end{array}$ \\
\hline DoPriceComparis. & & $\begin{array}{c}-0.39 \\
(0.23)+\end{array}$ & $\begin{array}{c}-0.31 \\
(0.23)\end{array}$ & $\begin{array}{c}-0.36 \\
(0.23)\end{array}$ & $\begin{array}{c}-0.31 \\
(0.23)\end{array}$ & $\begin{array}{c}-0.32 \\
(0.23)\end{array}$ & $\begin{array}{c}-0.26 \\
(0.23)\end{array}$ \\
\hline InternetForInfo & & $\begin{array}{c}0.01 \\
(0.18)\end{array}$ & $\begin{array}{c}-0.17 \\
(0.16)\end{array}$ & $\begin{array}{c}-0.14 \\
(0.17)\end{array}$ & $\begin{array}{c}-0.09 \\
(0.17)\end{array}$ & $\begin{array}{c}0.04 \\
(0.19)\end{array}$ & $\begin{array}{c}-0.09 \\
(0.16)\end{array}$ \\
\hline GatherMuchInfo & & $\begin{array}{c}-0.25 \\
(0.20)\end{array}$ & $\begin{array}{c}-0.28 \\
(0.21)\end{array}$ & $\begin{array}{c}-0.26 \\
(0.21)\end{array}$ & $\begin{array}{c}-0.24 \\
(0.21)\end{array}$ & $\begin{array}{c}-0.23 \\
(0.20)\end{array}$ & $\begin{array}{c}-0.24 \\
(0.21)\end{array}$ \\
\hline ReadCarMagazine & & $\begin{array}{c}0.21 \\
(0.17)\end{array}$ & $\begin{array}{c}0.23 \\
(0.17)\end{array}$ & $\begin{array}{c}0.22 \\
(0.17)\end{array}$ & $\begin{array}{c}0.28 \\
(0.17)+\end{array}$ & $\begin{array}{c}0.24 \\
(0.17)\end{array}$ & $\begin{array}{c}0.25 \\
(0.17)\end{array}$ \\
\hline VisitDealerForFun & & $\begin{array}{c}-0.10 \\
(0.20)\end{array}$ & $\begin{array}{c}-0.10 \\
(0.20)\end{array}$ & $\begin{array}{c}-0.11 \\
(0.20)\end{array}$ & $\begin{array}{c}-0.11 \\
(0.20)\end{array}$ & $\begin{array}{c}-0.13 \\
(0.20)\end{array}$ & $\begin{array}{c}-0.13 \\
(0.20)\end{array}$ \\
\hline CustomerAge & $\begin{array}{c}-0.13 \\
(0.14)\end{array}$ & $\begin{array}{c}-0.12 \\
(0.15)\end{array}$ & $\begin{array}{c}-0.09 \\
(0.15)\end{array}$ & $\begin{array}{c}-0.13 \\
(0.15)\end{array}$ & $\begin{array}{c}-0.11 \\
(0.14)\end{array}$ & $\begin{array}{c}-0.12 \\
(0.14)\end{array}$ & $\begin{array}{c}-0.10 \\
(0.15)\end{array}$ \\
\hline Education & $\begin{array}{c}-0.41 \\
(0.10) * *\end{array}$ & $\begin{array}{c}-0.39 \\
(0.10) * *\end{array}$ & $\begin{array}{c}-0.39 \\
(0.10) * *\end{array}$ & $\begin{array}{c}-0.41 \\
(0.10) * *\end{array}$ & $\begin{array}{c}-0.38 \\
(0.10) * *\end{array}$ & $\begin{array}{c}-0.39 \\
(0.10) * *\end{array}$ & $\begin{array}{c}-0.39 \\
(0.10) * *\end{array}$ \\
\hline Income & $\begin{array}{c}-0.23 \\
(0.25)\end{array}$ & $\begin{array}{c}-0.20 \\
(0.25)\end{array}$ & $\begin{array}{c}-0.20 \\
(0.25)\end{array}$ & $\begin{array}{c}-0.25 \\
(0.25)\end{array}$ & $\begin{array}{c}-0.20 \\
(0.25)\end{array}$ & $\begin{array}{c}-0.20 \\
(0.25)\end{array}$ & $\begin{array}{c}-0.20 \\
(0.25)\end{array}$ \\
\hline Income $^{2}$ & $\begin{array}{c}0.04 \\
(0.02)+\end{array}$ & $\begin{array}{c}0.04 \\
(0.02)+\end{array}$ & $\begin{array}{c}0.04 \\
(0.02)+\end{array}$ & $\begin{array}{c}0.05 \\
(0.02) *\end{array}$ & $\begin{array}{c}0.04 \\
(0.02) *\end{array}$ & $\begin{array}{c}0.04 \\
(0.02)+\end{array}$ & $\begin{array}{c}0.04 \\
(0.02)+\end{array}$ \\
\hline Black & $\begin{array}{c}0.52 \\
(0.88)\end{array}$ & $\begin{array}{c}0.69 \\
(0.87)\end{array}$ & $\begin{array}{c}0.67 \\
(0.87)\end{array}$ & $\begin{array}{c}0.68 \\
(0.87)\end{array}$ & $\begin{array}{c}0.68 \\
(0.87)\end{array}$ & $\begin{array}{c}0.68 \\
(0.87)\end{array}$ & $\begin{array}{c}0.66 \\
(0.87)\end{array}$ \\
\hline Hispanic & $\begin{array}{c}0.37 \\
(0.38)\end{array}$ & $\begin{array}{c}0.40 \\
(0.38)\end{array}$ & $\begin{array}{c}0.41 \\
(0.38)\end{array}$ & $\begin{array}{c}0.40 \\
(0.39)\end{array}$ & $\begin{array}{c}0.50 \\
(0.38)\end{array}$ & $\begin{array}{c}0.41 \\
(0.38)\end{array}$ & $\begin{array}{c}0.41 \\
(0.38)\end{array}$ \\
\hline OtherRace & $\begin{array}{c}0.24 \\
(0.44)\end{array}$ & $\begin{array}{c}0.28 \\
(0.42)\end{array}$ & $\begin{array}{c}0.31 \\
(0.42)\end{array}$ & $\begin{array}{c}0.20 \\
(0.44)\end{array}$ & $\begin{array}{c}0.34 \\
(0.43)\end{array}$ & $\begin{array}{c}0.27 \\
(0.42)\end{array}$ & $\begin{array}{c}0.30 \\
(0.43)\end{array}$ \\
\hline Female & $\begin{array}{c}0.48 \\
(0.26)+\end{array}$ & $\begin{array}{c}0.32 \\
(0.27)\end{array}$ & $\begin{array}{c}0.31 \\
(0.27)\end{array}$ & $\begin{array}{c}0.25 \\
(0.27)\end{array}$ & $\begin{array}{c}0.32 \\
(0.27)\end{array}$ & $\begin{array}{c}0.32 \\
(0.27)\end{array}$ & $\begin{array}{c}0.31 \\
(0.27)\end{array}$ \\
\hline Constant & $\begin{array}{c}1,007.30 \\
(1.43) * * \\
\end{array}$ & $\begin{array}{c}1,007.09 \\
(1.75) * * \\
\end{array}$ & $\begin{array}{c}1,007.18 \\
(1.76) * * \\
\end{array}$ & $\begin{array}{c}1,007.14 \\
(1.77) * * \\
\end{array}$ & $\begin{array}{c}1,007.62 \\
(1.76) * * \\
\end{array}$ & $\begin{array}{c}1,007.62 \\
(1.77) * * \\
\end{array}$ & $\begin{array}{c}1,007.71 \\
(1.77) * * \\
\end{array}$ \\
\hline Car Fixed Effects & yes & yes & yes & yes & yes & yes & yes \\
\hline Observations & 1436 & 1436 & 1436 & 1419 & 1435 & 1435 & 1435 \\
\hline R-squared & 0.96 & 0.96 & 0.96 & 0.96 & 0.97 & 0.97 & 0.97 \\
\hline
\end{tabular}

* significant at $5 \%$;* significant at $1 \% ;+$ significant at $10 \%$ level. Robust standard errors in parentheses.

${ }^{\dagger}$ Unreported are car, month, and region fixed effects, EndOfMonth, Weekend, TradeIn, Competition, VehicleCost, and census demographics.

Response scale on trait variables is 1="Disagree Strongly", 4=" Agree Strongly."

All coefficients are multiplied by 100 . 
Table 3: Price effects by bargaining disutility and Probit on Internet use ${ }^{\dagger}$

\begin{tabular}{|c|c|c|c|c|}
\hline Dep. Var. & $\begin{array}{c}(1) \\
\ln (\text { price }) \\
\end{array}$ & $\begin{array}{c}(2) \\
\ln (\text { price })\end{array}$ & $\begin{array}{c}(3) \\
\ln (\text { price }) \\
\end{array}$ & $\begin{array}{c}(4) \\
\text { InternetUse }\end{array}$ \\
\hline InternetUse & $\begin{array}{c}0.17 \\
(0.48)\end{array}$ & $\begin{array}{c}0.06 \\
(0.42)\end{array}$ & & \\
\hline DislikeBargaining & $\begin{array}{c}2.09 \\
(0.52)^{* *}\end{array}$ & $\begin{array}{c}1.97 \\
(0.54)^{* *}\end{array}$ & $\begin{array}{c}2.57 \\
(0.67)^{* *}\end{array}$ & \\
\hline InternetUse*DislikeBarg & $\begin{array}{c}-1.70 \\
(0.62)^{* *}\end{array}$ & $\begin{array}{c}-1.49 \\
(0.63)^{*}\end{array}$ & & \\
\hline OBSReferral & $\begin{array}{c}-0.83 \\
(0.46)+\end{array}$ & $\begin{array}{c}-0.74 \\
(0.40)+\end{array}$ & & \\
\hline OBSReferral*DislikeBarg & $\begin{array}{c}0.26 \\
(0.57)\end{array}$ & $\begin{array}{c}0.17 \\
(0.54)\end{array}$ & & \\
\hline Informed & & & $\begin{array}{c}0.49 \\
(0.51)\end{array}$ & \\
\hline Informed*DislikeBarg & & & $\begin{array}{c}-2.00 \\
(0.72)^{* *}\end{array}$ & \\
\hline \#DealersVisited & $\begin{array}{l}-0.29 \\
(0.14)^{*}\end{array}$ & $\begin{array}{c}-0.31 \\
(0.14)^{*}\end{array}$ & $\begin{array}{c}-0.35 \\
(0.14)^{*}\end{array}$ & \\
\hline DoPriceComparisons & $\begin{array}{l}-0.25 \\
(0.23)\end{array}$ & & $\begin{array}{l}-0.20 \\
(0.24)\end{array}$ & \\
\hline InternetForInfo & $\begin{array}{c}0.02 \\
(0.18)\end{array}$ & & $\begin{array}{l}-0.17 \\
(0.15)\end{array}$ & \\
\hline GatherMuchInfo & $\begin{array}{l}-0.23 \\
(0.20)\end{array}$ & & $\begin{array}{l}-0.29 \\
(0.20)\end{array}$ & \\
\hline ReadCarMagazine & $\begin{array}{c}0.21 \\
(0.16)\end{array}$ & & $\begin{array}{c}0.25 \\
(0.16)\end{array}$ & \\
\hline VisitDealerForFun & $\begin{array}{l}-0.12 \\
(0.20)\end{array}$ & & $\begin{array}{l}-0.10 \\
(0.20)\end{array}$ & \\
\hline WillingnessToSearch & & $\begin{array}{c}-0.29 \\
(0.16)+\end{array}$ & & $\begin{array}{c}0.76 \\
(0.05)^{* *}\end{array}$ \\
\hline CarEnthusiast & & $\begin{array}{c}0.05 \\
(0.13)\end{array}$ & & $\begin{array}{c}-0.18 \\
(0.04)^{* *}\end{array}$ \\
\hline BargainingDisutility & & & & $\begin{array}{c}0.16 \\
(0.04)^{* *}\end{array}$ \\
\hline CustomerAge & $\begin{array}{l}-0.07 \\
(0.14)\end{array}$ & $\begin{array}{l}-0.10 \\
(0.14)\end{array}$ & $\begin{array}{l}-0.04 \\
(0.14)\end{array}$ & $\begin{array}{c}-0.22 \\
(0.05)^{* *}\end{array}$ \\
\hline Education & $\begin{array}{c}-0.39 \\
(0.10)^{* *}\end{array}$ & $\begin{array}{c}-0.38 \\
(0.10)^{* *}\end{array}$ & $\begin{array}{c}-0.39 \\
(0.10)^{* *}\end{array}$ & $\begin{array}{c}0.06 \\
(0.03)^{*}\end{array}$ \\
\hline Income & $\begin{array}{l}-0.21 \\
(0.25)\end{array}$ & $\begin{array}{l}-0.18 \\
(0.25)\end{array}$ & $\begin{array}{l}-0.20 \\
(0.25)\end{array}$ & $\begin{array}{c}0.02 \\
(0.09)\end{array}$ \\
\hline Income $^{2}$ & $\begin{array}{c}0.04 \\
(0.02)+\end{array}$ & $\begin{array}{c}0.04 \\
(0.02)+\end{array}$ & $\begin{array}{c}0.04 \\
(0.02)+\end{array}$ & $\begin{array}{c}0.01 \\
(0.01)\end{array}$ \\
\hline Black & $\begin{array}{c}0.75 \\
(0.87)\end{array}$ & $\begin{array}{c}0.69 \\
(0.87)\end{array}$ & $\begin{array}{c}0.67 \\
(0.86)\end{array}$ & $\begin{array}{c}0.03 \\
(0.23)\end{array}$ \\
\hline Hispanic & $\begin{array}{c}0.42 \\
(0.38)\end{array}$ & $\begin{array}{c}0.38 \\
(0.38)\end{array}$ & $\begin{array}{c}0.39 \\
(0.38)\end{array}$ & $\begin{array}{c}-0.36 \\
(0.11)^{* *}\end{array}$ \\
\hline OtherRace & $\begin{array}{c}0.36 \\
(0.43)\end{array}$ & $\begin{array}{c}0.36 \\
(0.43)\end{array}$ & $\begin{array}{c}0.42 \\
(0.42)\end{array}$ & $\begin{array}{c}-0.02 \\
(0.20)\end{array}$ \\
\hline Female & $\begin{array}{c}0.39 \\
(0.27)\end{array}$ & $\begin{array}{c}0.34 \\
(0.27)\end{array}$ & $\begin{array}{c}0.38 \\
(0.27)\end{array}$ & $\begin{array}{l}-0.02 \\
(0.09)\end{array}$ \\
\hline Constant & $\begin{array}{l}1,007.80 \\
(1.75)^{* *}\end{array}$ & $\begin{array}{l}1,006.60 \\
(1.52)^{* *}\end{array}$ & $\begin{array}{l}1,007.93 \\
(1.77)^{* *}\end{array}$ & $\begin{array}{c}0.94 \\
(0.48)^{*}\end{array}$ \\
\hline Car Fixed Effects & yes & yes & yes & no \\
\hline Observations & 1435 & 1435 & 1435 & 1436 \\
\hline R-squared & 0.97 & 0.97 & 0.97 & \\
\hline
\end{tabular}

* significant at 5\%; ** significant at $1 \%$; + significant at $10 \%$ level. Robust standard errors in parentheses. All coefficients are multiplied by 100.

$\dagger$ Unreported are (columns 1-3) car, month, and region fixed effects, EndOfMonth, Weekend, TradeIn, Competition, VehicleCost, and (columns 1-4) census demographics.

Response scale on trait variables 1="Disagree Strongly", 4="Agree Strongly." 